\title{
An In Situ Evaluation of the Protective Effect of Nano Eggshell/Titanium Dioxide against Erosive Acids
}

\author{
Stanley Chibuzor Onwubu ${ }^{D},{ }^{1}$ Phumlane Selby Mdluli, ${ }^{2}$ Shenuka Singh ${ }^{(D)}{ }^{3}$ \\ Sanele Nyembe $\mathbb{D}^{\mathrm{D}}{ }^{4}$ and Rookmoney Thakur ${ }^{1}$ \\ ${ }^{1}$ Dental Sciences, Durban University of Technology (DUT), Durban, South Africa \\ ${ }^{2}$ Chemistry, Durban University of Technology (DUT), Durban, South Africa \\ ${ }^{3}$ Discipline of Dentistry, University of KwaZulu-Natal (UKZN), Durban, South Africa \\ ${ }^{4}$ DST/Mintek Nanotechnology Innovation Centre, Advanced Materials Division, Mintek, Private Bag X3015, Randburg, \\ Johannesburg 2125, South Africa \\ Correspondence should be addressed to Stanley Chibuzor Onwubu; 21445599@dut4life.ac.za
}

Received 18 August 2018; Revised 19 October 2018; Accepted 7 November 2018; Published 2 December 2018

Academic Editor: Louis M. Lin

Copyright (c) 2018 Stanley Chibuzor Onwubu et al. This is an open access article distributed under the Creative Commons Attribution License, which permits unrestricted use, distribution, and reproduction in any medium, provided the original work is properly cited.

\begin{abstract}
Objectives. Enamel erosion caused by high consumption of acidic drinks poses a significant public health concern. This study was aimed to determine the protective effect of eggshell-titanium dioxide composite $\left(\mathrm{EB} @ \mathrm{TiO}_{2}\right)$ against erosive acids on tooth enamel. Methods. Twenty prepared bovine tooth enamel specimens were randomly assigned to 5 sample groups $(n=4)$ : $(1)$ unexposed tooth enamel; (2) exposed tooth enamel + HCI; (3) exposed tooth enamel + HCI + Colgate toothpaste; (4) exposed tooth enamel + $\mathrm{HCI}+$ Sensodyne toothpaste; and (5) exposed tooth enamel + HCI + EB@TiO ${ }_{2}$. The mean roughness value $\left(R_{\mathrm{rms}}\right)$ of the exposed and unexposed tooth was measured with atomic force microscope (AFM). Scanning electron microscope (SEM) and Raman spectroscopy techniques were used to evaluate the surface morphology and changes. ANOVA was used to analyze the mean square roughness $\left(R_{\mathrm{rms}}\right)$ values for all specimens. Bonferonni correction was used to identify the mean differences among the 5 groups $(\alpha=0.05)$. The $R_{\mathrm{rms}}$ values measured for the unexposed and exposed specimens in HCI alone were statistically significant $(P<0.05)$. Results. No significant differences were found for the unexposed and exposed specimens in HCI + toothpaste and EB@ $\mathrm{TiO}_{2}$. The tooth enamel specimens exposed to HCI + Sensodyne had the highest $R_{\mathrm{rms}}$ values, while specimens exposed to HCI + $\mathrm{EB} @ \mathrm{TiO}_{2}$ had the lowest $R_{\mathrm{rms}}$ values. Conclusions. This study confirms that the investigated toothpaste provides protection against acidic substances. The study results further suggests that $\mathrm{EB} @ \mathrm{TiO}_{2}$ could be used to provide enhanced protection for tooth enamel.
\end{abstract}

\section{Introduction}

Enamel erosion has become a topical issue in recent years among clinicians and oral health-care providers due to the increase in the consumption of acidic drinks such as soft drinks, energy drinks, and fruit drinks [1]. Previous studies $[2,3]$ reported that these drinks have a $\mathrm{pH}[2-4]$ value that facilitates the dissolution of the tooth and the destruction of the mineral composition of the enamel. Several other authors $[4,5]$ have demonstrated that as a result of consumption of acidic drinks, the onset of caries and enamel erosion correlate positively together.
Whilst the tooth enamel is mainly composed of hydroxyapatite in the form of phosphate ions $\left(\mathrm{PO}_{4}{ }^{3-}\right)$ and calcium ions $\left(\mathrm{Ca}^{2+}\right)$, Shellis et al. [6], and Lussi and Carvalho [7] argued that there exists an equilibrium between the tooth enamel crystals and the surrounding oral environment. The destabilization of these equilibrium, particularly when the oral environment $\mathrm{pH}$ drops below a critical level (5.5 for enamel and 6.2 for dentin), may result in the dissolution of tooth mineral composition [8]. Moreover, the loss of enamel material by erosion is a dynamic process occasioned with periods of demineralization and remineralization (Figure 1); hence, preventive measures against enamel dissolution from 


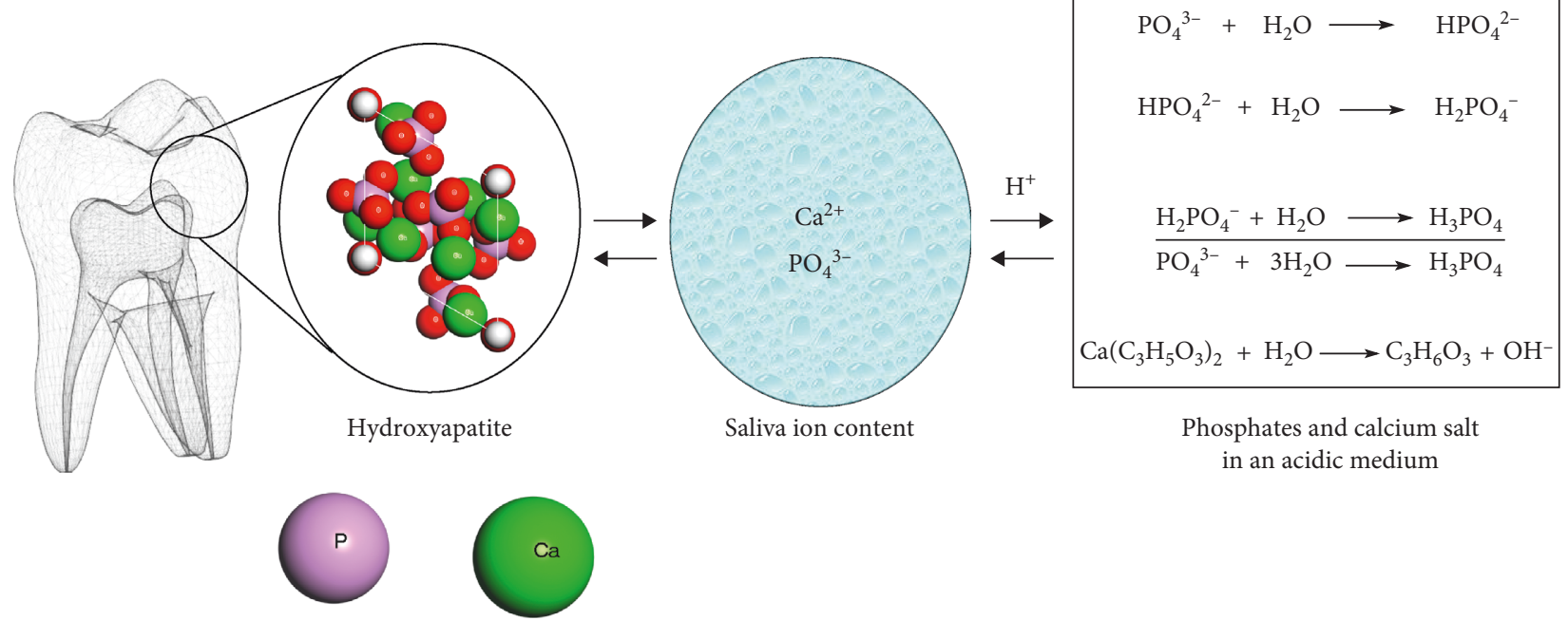

FIgURE 1: Illustration of tooth demineralization and remineralization dynamism in oral and acidic environment.

acid and potentially permanent damage should be a priority for oral health-care providers $[2,3]$.

Traditionally, toothpastes have been considered effective and accessible vehicles to improve enamel resistant against erosive oral environment [9]. In recent years, different ingredients have been added to the toothpastes composition to enhance their protective effect against erosive substances. Amongst these ingredients, the use of topical fluoride to modify the effects of erosion at the tooth surface is well documented [10-13]. However, Moron et al. [14] stressed that conventional fluoride-containing toothpastes lack the capacity to protect sufficiently well against erosive substance. Furthermore, Larsen and Richards [15] revealed that at $\mathrm{pH}$ below 3, the protective effect of fluoride is diminished. Consequently, it has been suggested that the beneficial health effects against erosive attacks can be improved with the addition of calcium or calcium containing material into toothpaste [16].

Significantly, studies by King'Ori [17] and Onwubu et al. [18] suggest that the calcium of eggshell can be used as an abrasive cleaner for dental plaque in toothpaste. Lin et al. [19] and Tao et al. [20] equally demonstrated that the mechanical modification of calcium carbonates together with titanium dioxide improved the acid resistance properties when used in paper making industry. However, there is a limited research on the protective effect of a modified eggshell-titanium dioxide composite $\left(\mathrm{EB} @ \mathrm{TiO}_{2}\right)$ on tooth enamel. This in vitro study aimed to determine the protective effect of a modified eggshell-titanium dioxide composite $\mathrm{EB} @ \mathrm{TiO}_{2}$ against erosive acids. The protective level of $\mathrm{EB} @ \mathrm{TiO}_{2}$ against erosive acids was compared against Colgate $^{\circledR}$ and Sensodyne ${ }^{\circledR}$ toothpaste. It was hypothesized that $\mathrm{EB} @ \mathrm{TiO}_{2}$ will offer more protection against erosive challenge than the commercial toothpastes.

\section{Materials and Methods}

2.1. Preparation of Eggshell-Titanium Dioxide Composite $\left(\mathrm{EB} @ \mathrm{TiO}_{2}\right)$. Modification of eggshell with titanium dioxide was achieved in two steps. In the first step, eggshells were prepared according to the procedure described by Onwubu et al. [21]. Eggshells were disinfected by storing them in a diluted solution of household sodium hypochlorite for six hours. Subsequently, eggshells were vacuum-dried for $\pm 6-$ $9 \mathrm{~min}$ at $250^{\circ} \mathrm{C}$. Thereafter, $30 \mathrm{~g}$ of the dried eggshell was placed in a $500 \mathrm{ml}$ stainless jar (inner diameter of $100 \mathrm{~mm}$ ), together with 50 stainless steel balls of $10 \mathrm{~mm}$ diameter, and dry-milled in a planetary ball mill (Retsch ${ }^{\circledR}$ PM 100) at $400 \mathrm{rpm}$ for 20 minutes. The collected powder was sieved to a particle size of $\leq 25 \mu \mathrm{m}$ using a mechanical sieving shaker (Retsch AS 200, Germany). In the next step, $20 \mathrm{~g}$ of the fine eggshell powder obtained in step 1 was modified by adding $5 \mathrm{~g}$ of anatase titanium dioxide $(\leq 15 \mu \mathrm{m})$. The mixture was subsequently ball-milled for $200 \mathrm{~min}$ to obtain eggshell-titanium dioxide composite $\left(\mathrm{EB} @ \mathrm{TiO}_{2}\right)$. The particle size distribution of the composite measured using high-resolution transmission microscope (TEM-Philips CM 120 model) at $120 \mathrm{kV}$ and image J software (National Institute of Health USA, http:// imagej.nih.gov./ij) was found to be $14 \mathrm{~nm}$ (Figure 2).

2.2. $\mathrm{pH}$ Measurement. The $\mathrm{pH}$ and buffering characteristics of the $\mathrm{EB} @ \mathrm{TiO}_{2}$ (tested samples) and the respective toothpastes, brand names, and manufacturers are given in Table 1 . The $\mathrm{pH}$ of each of the samples in deionized water as well as in $0.01 \mathrm{~mol} \cdot \mathrm{L}^{-1}$ hydrochloric acid (HCI) were measured by placing $1.5 \mathrm{~g}$ of each samples in a beaker containing $50 \mathrm{~mL}$ deionized and HCI, respectively. The solution was constantly agitated at low speed of $600 \mathrm{rpm}$ for $30 \mathrm{~min}$. A pH meter (Starter 300, Ohaus Incorporation USA) equipped with temperature sensor was used to record changes in the $\mathrm{pH}$ reading. Before testing the samples, the $\mathrm{pH}$ was calibrated using tested buffer of known $\mathrm{pH}$ solutions.

2.3. Preparation of Tooth Enamel Specimens. Twenty freshly collected bovine enamel anterior teeth were used to evaluate the acid resistant properties of $\mathrm{EB} @ \mathrm{TiO}_{2}$. The collected teeth were subsequently cleaned and disinfected in $10 \%$ chloroxylenol solution. Enamel specimens measuring $5 \mathrm{~mm} \times$ $5 \mathrm{~mm} \times 3 \mathrm{~mm}$ was prepared after cutting off the roots using a 


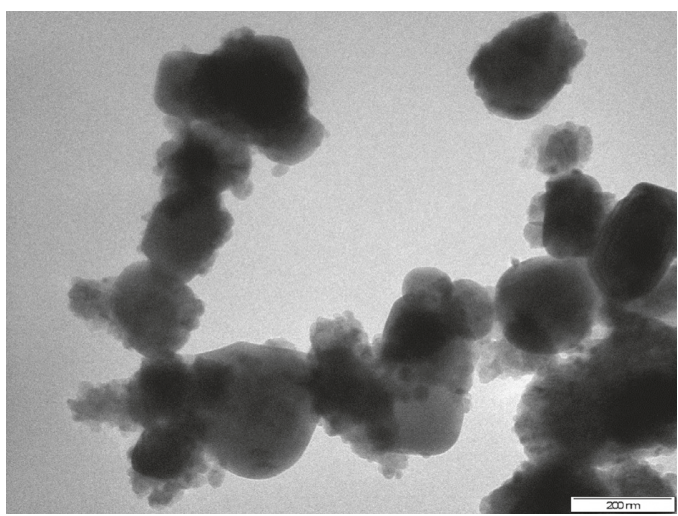

(a)

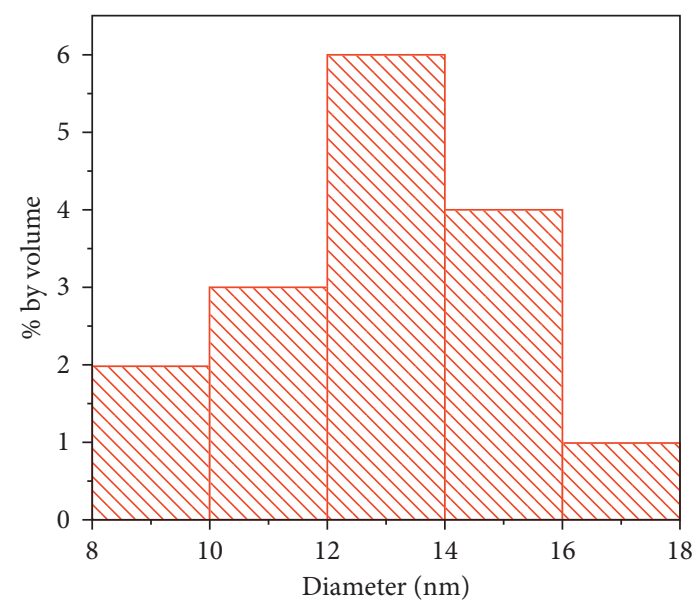

(b)

Figure 2: TEM image of (a) $\mathrm{EB} @ \mathrm{TiO}_{2}$ composite; (b) particle size distribution.

TABLE 1: Toothpastes used and their respective $\mathrm{pH}$ and buffering characteristics.

\begin{tabular}{|c|c|c|c|c|}
\hline Toothpastes & Brand name & Manufacturer & $\mathrm{pH}$ in deionized water & Buffering capacity $\mathrm{B}\left(\mathrm{mmol} 2^{-1} \mathrm{pH}^{-1}\right)$ \\
\hline Colgate & CALCI $^{\mathrm{TM}}$-SEAL protection & Colgate-Palmolive Co & 9.61 & $6.6 \pm 02.9$ \\
\hline Sensodyne & Rapid relief & GlaxoSmithKline & 7.41 & $2.3 \pm 0.02$ \\
\hline EB@TiO2 & N/A & Researcher & 9.31 & $7.3 \pm 0.11$ \\
\hline
\end{tabular}

low-speed diamond saw under water cooling conditions. Before subjecting the specimens to acidic condition, the specimens were embedded in a resin (FT 160; AMT composite), and a silicone mold (Blue mold; Agar scientific) was used to make a mounting base. The embedded specimens were randomly assigned into five groups $(n=4)$ and were then exposed to $0.01 \mathrm{~mol} \cdot \mathrm{L}^{-1} \mathrm{HCI}(\mathrm{pH}=2)$ for $30 \mathrm{~min}$ as follows: Group 1: unexposed tooth enamel; Group 2: exposed tooth enamel + HCI; Group 3: exposed tooth enamel + HCI + Colgate; Group 4: exposed tooth enamel + HCI + Sensodyne;

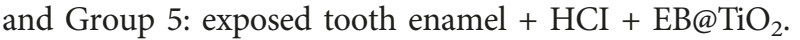

After $30 \mathrm{~min}$ of acid exposure, the specimens were rinsed in deionized water for $30 \mathrm{~s}$ and blot-dried.

2.4. Atomic Force Microscopy (AFM) Analysis. AFM (Nanoscope; Bruker) was used to analyze the mean square roughness $\left(R_{\text {rms }}\right)$ values of the specimens. The instrument was set in contact mode with a scanning size of $10 \mu \mathrm{m}$ and a scan rate of $2.394 \mathrm{~Hz}$. For each specimen, 5 different measurements of the $R_{\text {rms }}$ values were made. The average measured $R_{\text {rms }}$ values were then used for the statistical analysis.

2.5. Field-Scanning Electron Microscope Evaluation of the Specimens. The surface of the exposed and unexposed specimens was characterized using scanning electron microscope (FESEM; Carl Zeiss). As a proxy measure, a specimen from each group was analyzed microscopically.

2.6. Raman Spectroscopy Analysis of Specimens. The changes in the mineral content of the specimens were observed using a Raman (Perkin Elmer precisely Raman-station 400). The Raman analysis was done on the all the samples with the laser power set at $70 \mathrm{~mW}$, exposure every 10 seconds for 3 seconds at a time. Five different measurements were done for each samples and the average was used for statistical analysis.

2.7. Statistical Analysis. The mean roughness $\left(R_{\mathrm{rms}}\right)$ value of the specimens was evaluated with 1-way analysis of variance (ANOVA) by means of statistical software (IBM SPSS Statistics v25; IBM Corp.), followed by Bonferonni correction and the significance level was set at $\alpha=0.05$. For Raman analysis, the base line correction was estimated by the polynomial fitting method, and the peak area and height were determined from the Gaussian plot using Origin Pro software (OriginLab Corporation v 8).

\section{Results}

3.1. Atomic Force Microscopy (AFM). The 1-way ANOVA, mean, standard deviation, and standard error results are shown in Table 2. A notable statistical difference was observed in the mean surface roughness $\left(R_{\text {rms }}\right)$ for the unexposed and exposed specimens $(P<0.05)$.

Comparing the unexposed specimens (group 1) with specimens exposed to HCI alone (group 2), a significant difference were measured $(P<0.05)$. The unexposed specimens had the lowest mean $R_{\mathrm{rms}}(32.6 \pm 16.3 \mathrm{~nm})$ values while specimens exposed to $\mathrm{HCI}$ alone had the highest value (101.9 $\pm 18.0 \mathrm{~nm}$ ). No significant differences were measured for the unexposed specimens and the specimens exposed in groups 3 , 4 , and 5 , respectively $(P>0.05)$. AFM micrograph shown in Figure 3 further illustrates the surface profile of the specimens. The surface roughness appeared more pronounced for Figures 3(b)-3(d) when compared against Figures 3(a) and $3(\mathrm{e})$. 
TABLE 2: Mean surface roughness, standard deviation, standard error, and ANOVA.

\begin{tabular}{|c|c|c|c|c|c|c|c|}
\hline \multirow[t]{2}{*}{ Groups } & \multirow[t]{2}{*}{$N$} & \multirow[t]{2}{*}{ Mean \pm SD } & \multirow[t]{2}{*}{ Std. error } & \multicolumn{2}{|c|}{$\begin{array}{l}\text { 95\% confidence interval for } \\
\text { mean }\end{array}$} & \multirow[t]{2}{*}{$P$} & \multirow{2}{*}{$\begin{array}{c}\text { Post hoc bonferroni test } \\
\qquad P\end{array}$} \\
\hline & & & & Lower bound & Upper bound & & \\
\hline Unexposed tooth & 4 & $32.6 \pm 16.3 \mathrm{~nm}$ & 8.1 & 6.7077 & 58.5478 & \multirow{5}{*}{0.021} & $0.02^{1,2}$ \\
\hline Exposed tooth $+\mathrm{HCI}$ & 4 & $101.9 \pm 18.0 \mathrm{~nm}$ & 9.0 & 73.1958 & 130.5232 & & $0.295^{1,5}$ \\
\hline Exposed tooth + HCI + Colgate & 4 & $65.2 \pm 29.0 \mathrm{~nm}$ & 14.5 & 19.0787 & 111.4123 & & $0.992^{1,3}$ \\
\hline Exposed tooth $+\mathrm{HCI}+$ Senosdyne & 4 & $83.1 \pm 33.7 \mathrm{~nm}$ & 16.8 & 29.4663 & 136.6767 & & $0.159^{1,4}$ \\
\hline Exposed tooth + EB@ & 4 & $57.2 \pm 29.6 \mathrm{~nm}$ & 14.8 & 10.0747 & 104.3583 & & $1.00^{1,5}$ \\
\hline
\end{tabular}

Superscript numbers indicate significant differences between the sample groups (ANOVA, $P<0.05$ ).
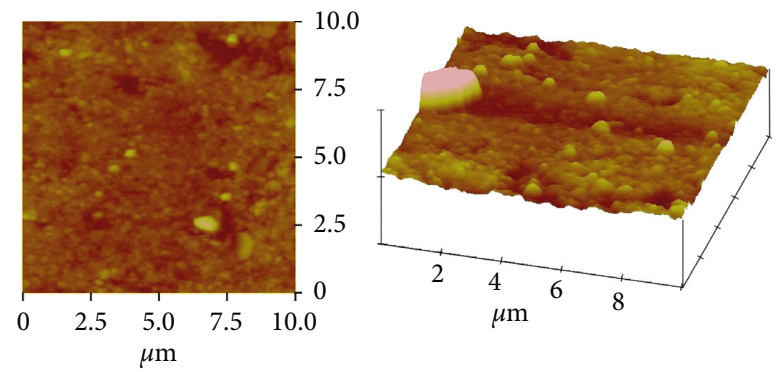

(a)
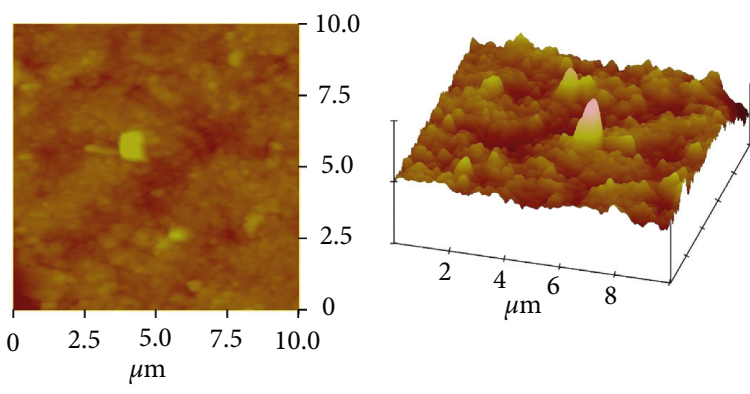

(c)
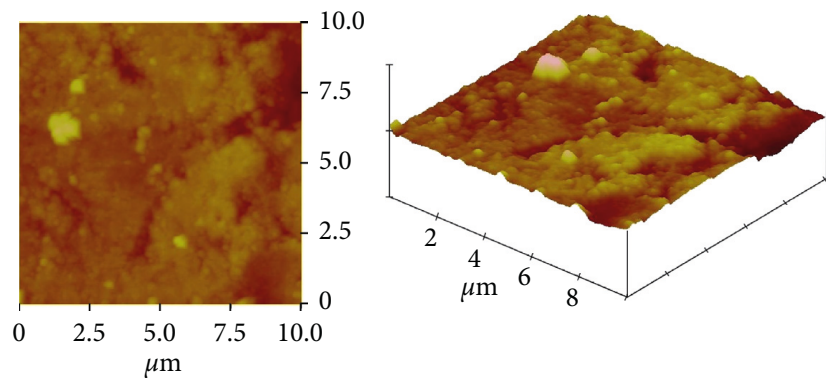

(e)

Figure 3: AFM profile of (a) unexposed tooth; (b) after exposure to HCI; (c) after exposure to HCI + Colgate toothpaste; (d) after exposure

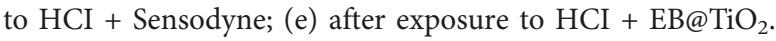

3.2. Field-Scanning Electron Microscope Observation of Specimens. The FESEM images of the specimens are shown in Figure 4. The images revealed surface differences between the unexposed specimens, exposed tooth alone, and the test groups (EB@ $\mathrm{TiO}_{2}$ and commercial toothpastes). While using the unexposed specimen to benchmark the demineralization of the exposed sample groups, the images in Figures 4(b) and 3(d) visibly showed evidence of the prismatic destruction of the hydroxyapatites which suggest erosion of tooth specimens exposed to acid
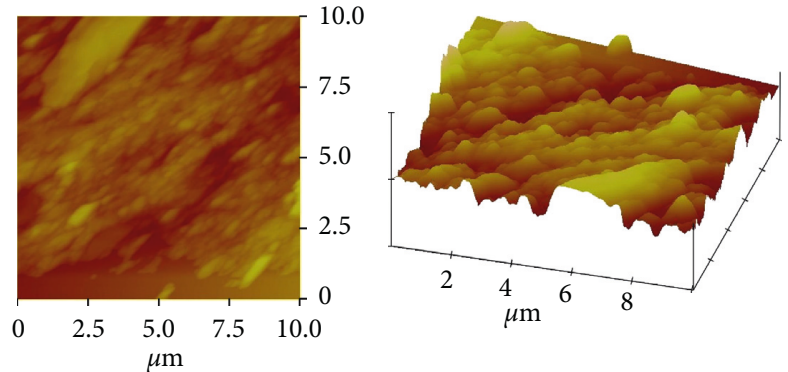

(b)
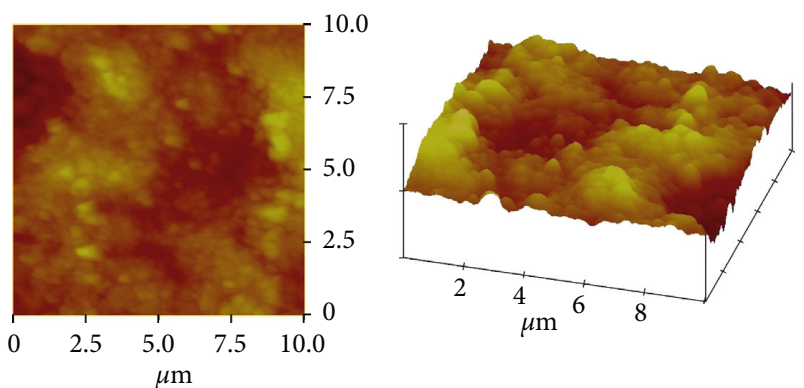

(d) alone and the Sensodyne toothpaste. In contrast, the tooth specimen exposed to acid in the presence of both EB@ $\mathrm{TiO}_{2}$ and Colgate showed less evidence of the prismatic destruction of the enamel (Figures 4(c) and 3(e)).

3.3. Raman Spectroscopy. Furthermore, the changes in the position of phosphates $\left(\mathrm{V}_{3}\left(\mathrm{PO}_{4}{ }^{3-}\right)\right)$ peaks for the unexposed and exposed specimens are given in Figure 4. In the unexposed specimens, the peak was only slightly prominent 


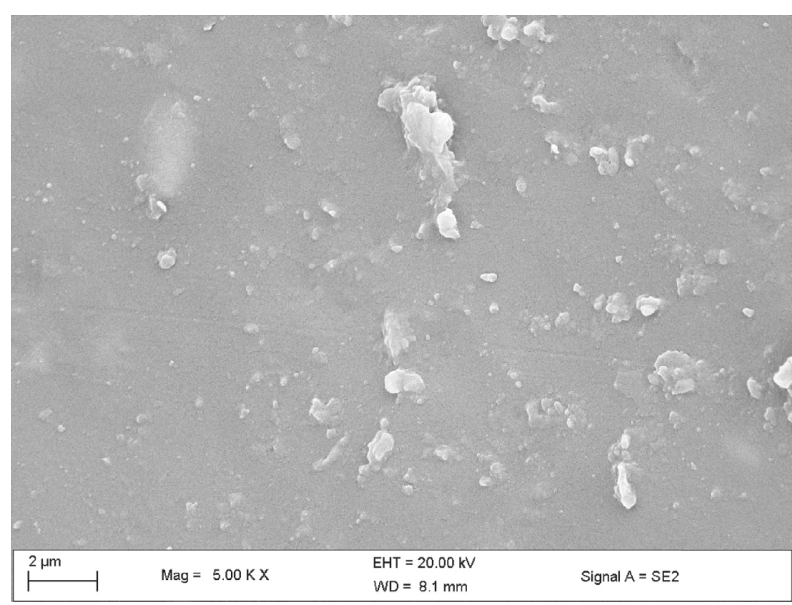

(a)

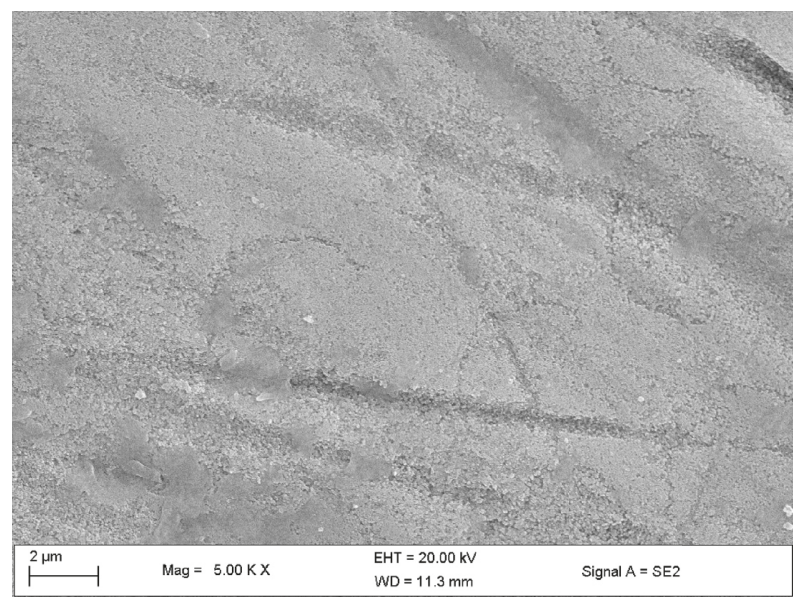

(c)

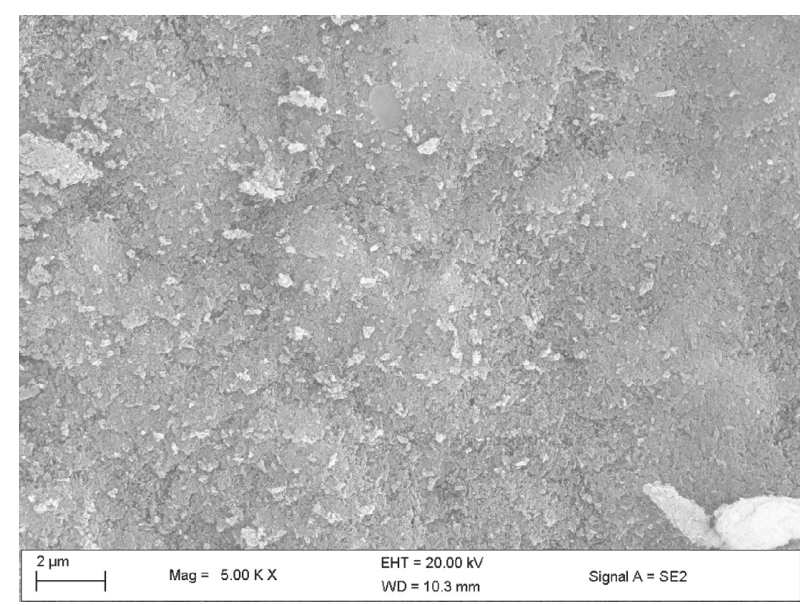

(b)

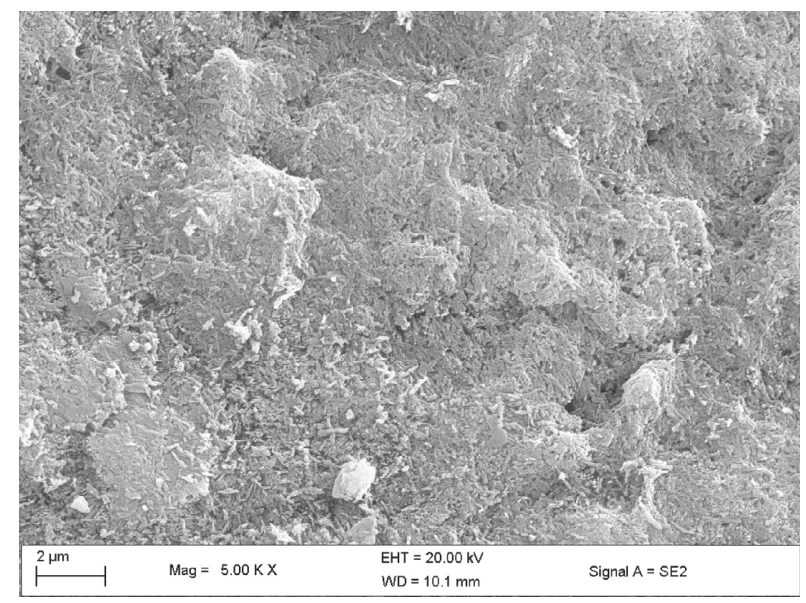

(d)

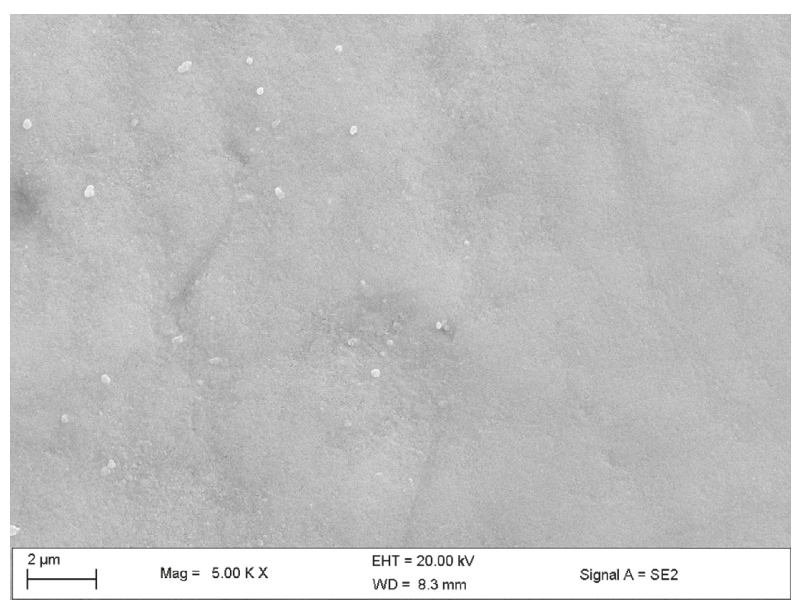

(e)

FIgURE 4: FESEM images of (a) unexposed tooth; (b) after exposure to HCI; (c) after exposure to HCI + Colgate toothpaste; (d) after

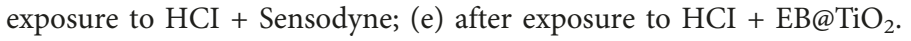

(Figure 5(e)). On the other hand, the peaks for the specimen exposed in HCI alone (Figure 5(a)) were distinctly prominent to a considerable height (Table 3 ). Moreover, only slight changes were noticed in the peaks of the specimens exposed to sample groups 3 (Figure 5(c)), 4 (Figure 5(b)), and 5 (Figure 5(d)), respectively.

\section{Discussion}

The purpose of this study was to examine the protective effect of a modified eggshell-titanium dioxide composite $\left(\mathrm{EB} @ \mathrm{TiO}_{2}\right)$ in comparison with some commercial toothpastes against erosive acids. In line with suggested 


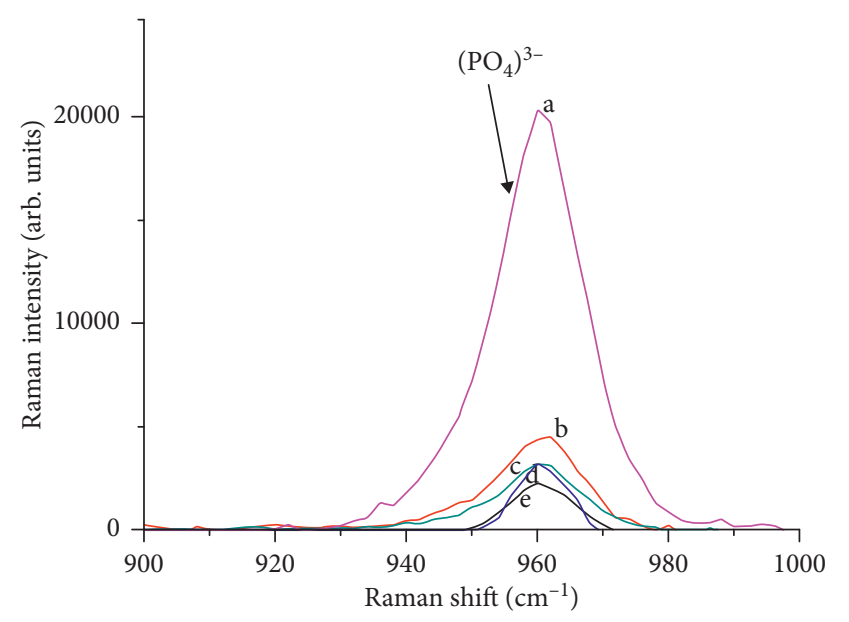

Figure 5: Raman spectrum obtained for tooth samples (a) expose to HCI alone; (b) expose to HCI + Sensodyne; (c) exposed HCI +

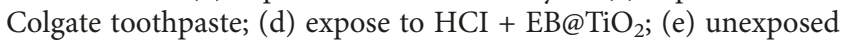
tooth.

Table 3: Peak analysis as determine by the Gaussian plot.

\begin{tabular}{lcc}
\hline \multirow{2}{*}{ Sample groups } & \multicolumn{2}{c}{ Peak parameters } \\
& Height & Area \\
\hline Unexposed tooth & 2454.2 & 32769.3 \\
Tooth exposed to HCI & 18853.3 & 345765.1 \\
Tooth exposed to HCI + Colgate toothpaste & 3956.9 & 52589.4 \\
Tooth exposed to HCI + Sensodyne & 4270.3 & 73357.7 \\
Tooth exposed to HCI + ${\mathrm{EB} @ \mathrm{TiO}_{2}}^{2}$ & 2965.9 & 49185.4 \\
\hline
\end{tabular}

techniques in the literature [22-24], AFM was used to characterize and measure the changes in the surface roughness pre- and postexposure to HCI. The average mean square roughness values $\left(R_{\mathrm{rms}}\right)$ measured were used for statistical analysis. The $R_{\mathrm{rms}}$ is the standard deviation height obtained from the AFM images (Figure 3 ) in areas of $30 \times 30 \mu \mathrm{m}^{2}$ with a resolution of $256 \times 256$ pixels. The $R_{\text {rms }}$ data demonstrated that exposure of tooth enamel to HCI significantly affected the surface roughness $(P<0.05)$.

More so, the $R_{\mathrm{rms}}$ values measured for the enamel tooth specimens exposed to HCI alone group were significantly higher than the unexposed tooth enamel $(P<0.05)$. This strongly confirmed that the exposure of enamel to acidic substances leads to enamel demineralization. Whilst tooth enamel comprises mostly of calcium $\left(\mathrm{Ca}^{2+}\right)$, phosphates $\left(\mathrm{PO}_{4}{ }^{3+}\right)$, and hydroxide $\left(\mathrm{OH}^{-}\right)$, the enamel is constantly in equilibrium with the surrounding saliva and enamel crystals. In support of Shellis et al. [6], the exposure of the tooth enamel to $\mathrm{HCI}$ alone may cause enamel to release more ions to the environment to attain a new state of equilibrium. Consequently, and consistent with Lussi and Carvalho [7], the acidic condition exacerbated the process leading to enamel demineralization (Figure 4(b)).

This notwithstanding, the $R_{\text {rms }}$ values measured for the enamel tooth specimen exposed to Colgate, Sensodyne, and $\mathrm{EB} @ \mathrm{TiO}_{2}$ were not different from the unexposed tooth $(P>0.05)$. In light of these, it can be inferred that the toothpastes (Colgate and Sensodyne) and test group $\left(\mathrm{EB} @ \mathrm{TiO}_{2}\right)$ were protective against enamel demineralization. This supports the notion that the sampled toothpastes are effective and accessible vehicles to improve enamel resistant against erosive oral environment [9]. In comparing the protective effect of the sampled toothpastes samples against $\mathrm{EB} @ \mathrm{TiO}_{2}$, the $R_{\mathrm{rms}}$ values with the highest mean was for Sensodyne and the lowest for $\mathrm{EB} @ \mathrm{TiO}_{2}$ (Table 2). This could have been attributed to the presence of $\mathrm{Ca}$ and or titanium ions in the exposed tooth in the presence of $\mathrm{EB}_{0} \mathrm{TiO}_{2}$. More so, and given the differences in the mean $R_{\mathrm{rms}}$ values between $\mathrm{EB} @ \mathrm{TiO}_{2}$ and Colgate toothpaste, the observed differences appear to reflect the buffering capacities of the 2 groups (Table 1). This strongly supports Caneppele et al. [25] that the buffering capacity of acidic concentration is critical in erosive potential of acidic substance, which may influence the dissolution rate of the enamel. Equally, the differences in the $R_{\mathrm{rms}}$ values between $\mathrm{EB} @ \mathrm{TiO}_{2}$ and Colgate toothpastes may also be associated with the modification of the calcium carbonate constituents of eggshell with titanium dioxide. Hence, the tested hypothesis is partially accepted as the $\mathrm{EB} @ \mathrm{TiO}_{2}$ composite effectively protected the tooth enamel against erosion.

Furthermore, the Raman spectrum of the exposed and unexposed tooth enamel observed at a peak of $960 \mathrm{~cm}^{-1}$ could be attributed to the symmetrical stretching of the tetrahedron oxygen atoms that surrounds the phosphorus atoms [26, 27]. This result is consistent with Ionita [28] that Raman spectrum of healthy enamel and demineralized tooth is observed at a well-defined peak at $959 \mathrm{~cm}^{-1}$ vibrations. Moreover, the highest-Raman spectrum demineralization intensity observed for the exposed tooth alone in HCI was nearly 5 -times greater than the intensity measured for the unexposed tooth (Figure 5). In addition, He et al. [29] and Targino et al. [30] theorize that the mineral intensity measured in Raman could be a factor that determines the rate of demineralization of tooth enamel. Significantly, the Raman intensity measured for $\mathrm{EB} @ \mathrm{TiO}_{2}$ was comparable to those measured for Colgate toothpaste; however, it was lower than the sampled Sensodyne toothpaste (Figure 5). This observation is consistent with the results of Joiner et al. [16] which show that the addition of calcium and or calcium containing materials into toothpaste improves its resistant against acidic erosion on tooth enamel.

In light of the above findings, the researchers plan to further examine the remineralization potential of $\mathrm{EB} @ \mathrm{TiO}_{2}$, particularly in the repair of damaged tooth (enamel and dentine). These studies would help establish the suitability of $\mathrm{EB} @ \mathrm{TiO}_{2}$ in the maintenance of oral health particularly as a desensitising toothpaste.

\section{Conclusion}

In conclusion, this study has demonstrated that toothpastes provide protection to the tooth enamel against erosive substance. Notably, the study has shown that $\mathrm{EB} @ \mathrm{TiO}_{2}$ offer better protective covering to the enamel against acid attack. 


\section{Data Availability}

The data used to support the findings of this study are included within the article.

\section{Conflicts of Interest}

No conflicts of interest declared.

\section{Acknowledgments}

The authors acknowledge the financial support from the National Research Foundation of South Africa (no. 104824).

\section{References}

[1] D. Gambon, H. Brand, and E. Veerman, "Dental erosion in the 21st century: what is happening to nutritional habits and lifestyle in our society?," British Dental Journal, vol. 213, no. 2, pp. 55-57, 2012.

[2] M. Lombardini, M. Ceci, M. Colombo, S. Bianchi, and C. Poggio, "Preventive effect of different toothpastes on enamel erosion: AFM and SEM studies," Scanning, vol. 36, no. 4, pp. 401-410, 2014.

[3] N. West, J. Seong, N. Hellin, H. Eynon, M. Barker, and T. He, "A clinical study to measure anti-erosion properties of a stabilized stannous fluoride dentifrice relative to a sodium fluoride/triclosan dentifrice," International Journal of Dental Hygiene, vol. 15, no. 2, pp. 113-119, 2017.

[4] M. Harding, H. Whelton, D. O’Mullane, and M. Cronin, "Dental erosion in 5-year-old Irish school children and associated factors: a pilot study," Community Dental Health, vol. 20, no. 3, pp. 165-170, 2003.

[5] Y. Luo, X. Zeng, M. Du, and R. Bedi, "The prevalence of dental erosion in preschool children in China," Journal of Dentistry, vol. 33, no. 2, pp. 115-121, 2005.

[6] R. P. Shellis, J. D. Featherstone, and A. Lussi, "Understanding the chemistry of dental erosion," in Erosive Tooth Wear, pp. 163-179, Karger Publishers, Basel, Switzerland, 2014.

[7] A. Lussi and T. S. Carvalho, "Analyses of the erosive effect of dietary substances and medications on deciduous teeth," PLoS One, vol. 10, no. 12, Article ID e0143957, 2015.

[8] A. Lussi and T. Jaeggi, "Erosion-diagnosis and risk factors," Clinical Oral Investigations, vol. 12, no. S1, pp. 5-13, 2008.

[9] M. Kato, M. Lancia, S. Sales-Peres, and M. Buzalaf, "Preventive effect of commercial desensitizing toothpastes on bovine enamel erosion in vitro," Caries Research, vol. 44, no. 2 , pp. 85-89, 2010.

[10] C. Ganss, K. Schulze, and N. Schlueter, "Toothpaste and erosion," in Toothpastes, Karger Publishers, Basel, Switzerland, 2013.

[11] N. A. Almosa, T. Lundgren, A. M. Aldrees, D. Birkhed, and H. Kjellberg, "Diagnosing the severity of buccal caries lesions in governmental and private orthodontic patients at debonding, using the ICDAS-II and the DIAGNOdent Pen," The Angle Orthodontist, vol. 84, no. 3, pp. 430-436, 2013.

[12] J. Krithikadatta, C. Fredrick, M. Abarajithan, and D. Kandaswamy, "Remineralisation of occlusal white spot lesion with a combination of $10 \%$ CPP-ACP and $0.2 \%$ sodium fluoride evaluated using diagnodent: a pilot study," Oral Health \& Preventive Dentistry, vol. 11, no. 2, pp. 191-196, 2013.

[13] M. Barbour, M. Finke, D. Parker, J. Hughes, G. Allen, and M. Addy, "The relationship between enamel softening and erosion caused by soft drinks at a range of temperatures," Journal of Dentistry, vol. 34, no. 3, pp. 207-213, 2006.

[14] B. M. Moron, S. Miyazaki, N. Ito et al., "Impact of different fluoride concentrations and $\mathrm{pH}$ of dentifrices on tooth erosion/abrasion in vitro," Australian Dental Journal, vol. 58, no. 1, pp. 106-111, 2013.

[15] M. Larsen and A. Richards, "Fluoride is unable to reduce dental erosion from soft drinks," Caries Research, vol. 36, no. 1, pp. 75-80, 2002.

[16] A. Joiner, F. Schäfer, K. Hornby et al., "Enhanced enamel benefits from a novel fluoride toothpaste," International Dental Journal, vol. 59, no. S4, pp. 244-253, 2009.

[17] A. King'Ori, "A review of the uses of poultry eggshells and shell membranes," International Journal of Poultry Science, vol. 10, no. 11, pp. 908-912, 2011.

[18] S. Onwubu, A. Vahed, S. Singh, and K. Kanny, "Physicochemical characterization of a dental eggshell powder abrasive material," Journal of Applied Biomaterials and Functional Materials, vol. 15, no. 4, 2017.

[19] H. Lin, Y.-b. Dong, and L.-y. Jiang, "Preparation of calcium carbonate particles coated with titanium dioxide," International Journal of Minerals, Metallurgy and Materials, vol. 16, no. 5, pp. 592-597, 2009.

[20] H. Tao, Y. He, and X. Zhao, "Preparation and characterization of calcium carbonate-titanium dioxide core-shell $\left(\mathrm{CaCO}_{3} @\right.$ $\mathrm{TiO}_{2}$ ) nanoparticles and application in the papermaking industry," Powder Technology, vol. 283, pp. 308-314, 2015.

[21] S. C. Onwubu, A. Vahed, S. Singh, and K. M. Kanny, "Reducing the surface roughness of dental acrylic resins by using an eggshell abrasive material," Journal of Prosthetic Dentistry, vol. 117, no. 2, pp. 310-314, 2017.

[22] R. Shellis, M. Barbour, S. Jones, and M. Addy, "Effects of $\mathrm{pH}$ and acid concentration on erosive dissolution of enamel, dentine, and compressed hydroxyapatite," European Journal of Oral Sciences, vol. 118, no. 5, pp. 475-482, 2010.

[23] I.-H. Kim, J. S. Son, B. K. Min, Y. K. Kim, K.-H. Kim, and T.-Y. Kwon, "A simple, sensitive and non-destructive technique for characterizing bovine dental enamel erosion: attenuated total reflection Fourier transform infrared spectroscopy," International Journal of Oral Sciences, vol. 8, no. 1, pp. 54-60, 2016.

[24] D. L. Pereira, A. Z. Freitas, L. Bachmann, C. Benetti, D. M. Zezell, and P. A. Ana, "Variation on molecular structure, crystallinity, and optical properties of dentin due to Nd: YAG laser and fluoride aimed at tooth erosion prevention," International Journal of Molecular Sciences, vol. 19, no. 2, p. 433, 2018.

[25] T. M. F. Caneppele, R. D. I. Jeronymo, R. Di Nicoló, M. A. M. de Araújo, and L. E. S. Soares, "In Vitro assessment of dentin erosion after immersion in acidic beverages: surface profile analysis and energy-dispersive X-ray fluorescence spectrometry study," Brazilian Dental Journal, vol. 23, no. 4, pp. 373-378, 2012.

[26] R. Ramakrishnaiah, R. Gu, S. Basavarajappa et al., "Applications of Raman spectroscopy in dentistry: analysis of tooth structure," Applied Spectroscopy Reviews, vol. 50, no. 4, pp. 332-350, 2015.

[27] J. Silveira, S. Coutinho, D. Marques et al., "Raman spectroscopy analysis of dental enamel treated with whitening product-Influence of saliva in the remineralization," Spectrochimica Acta Part A: Molecular and Biomolecular Spectroscopy, vol. 198, pp. 145-149, 2018. 
[28] I. Ionita, "Diagnosis of tooth decay using polarized microRaman confocal spectroscopy," Romanian Reports in Physics, vol. 61, pp. 567-574, 2009.

[29] B. He, S. Huang, C. Zhang, J. Jing, Y. Hao, and L. Xiao, "Mineral densities and elemental content in different layers of healthy human enamel with varying teeth age," Archives of Oral Biology, vol. 56, no. 10, pp. 997-1004, 2011.

[30] A. G. Targino, A. Rosenblatt, A. F. Oliveira, A. M. Chaves, and V. E. Santos, "The relationship of enamel defects and caries: a cohort study," Oral Diseases, vol. 17, no. 4, pp. 420-426, 2011. 


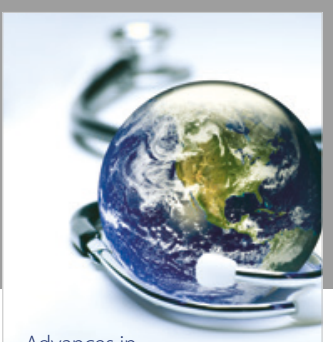

Advances in
Public Health

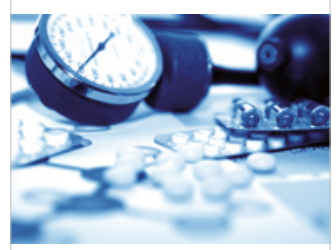

Case Reports in

Medicine

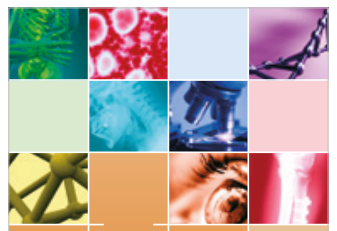

niernational Journal of

Biomaterials
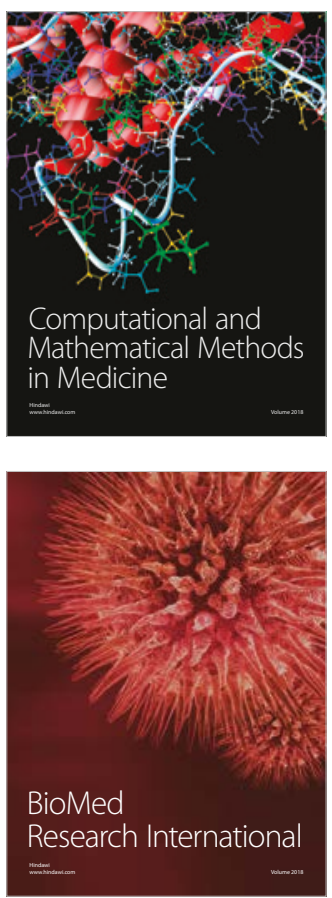

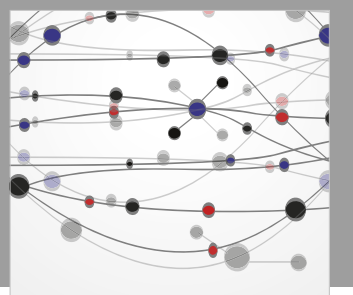

The Scientific World Journal Dentistry

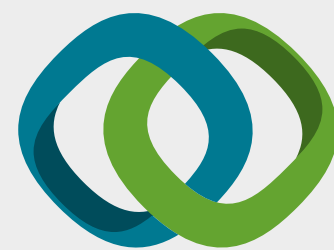

Hindawi

Submit your manuscripts at

www.hindawi.com
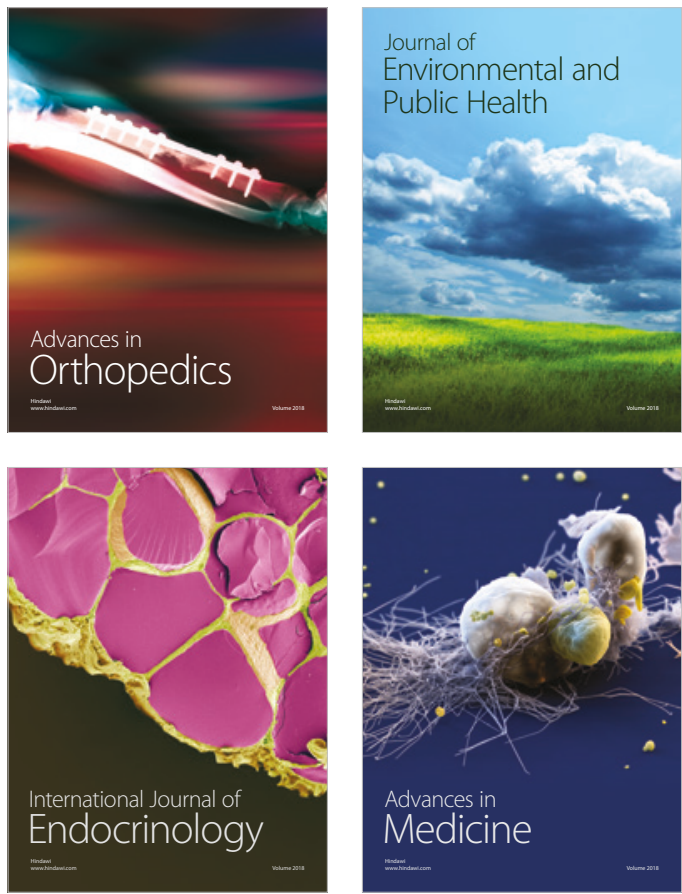
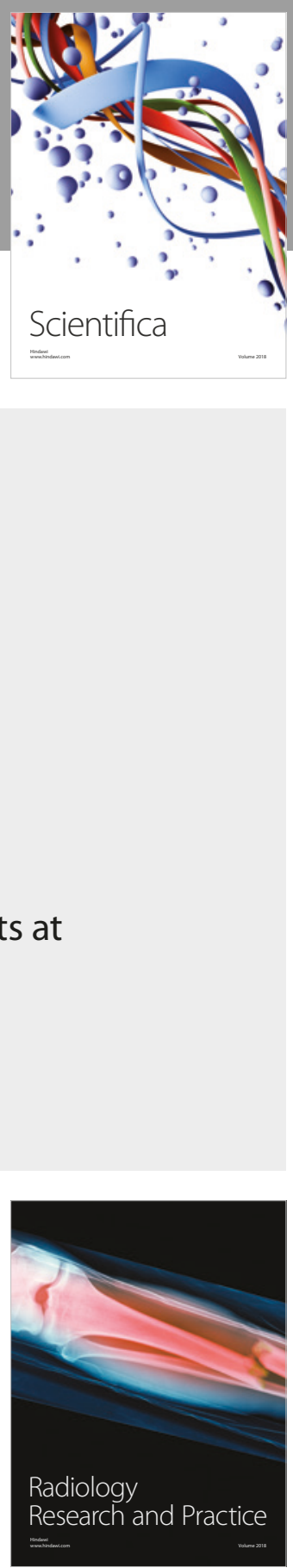

Scientifica

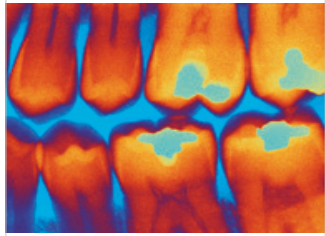

Case Reports in

Dentistry
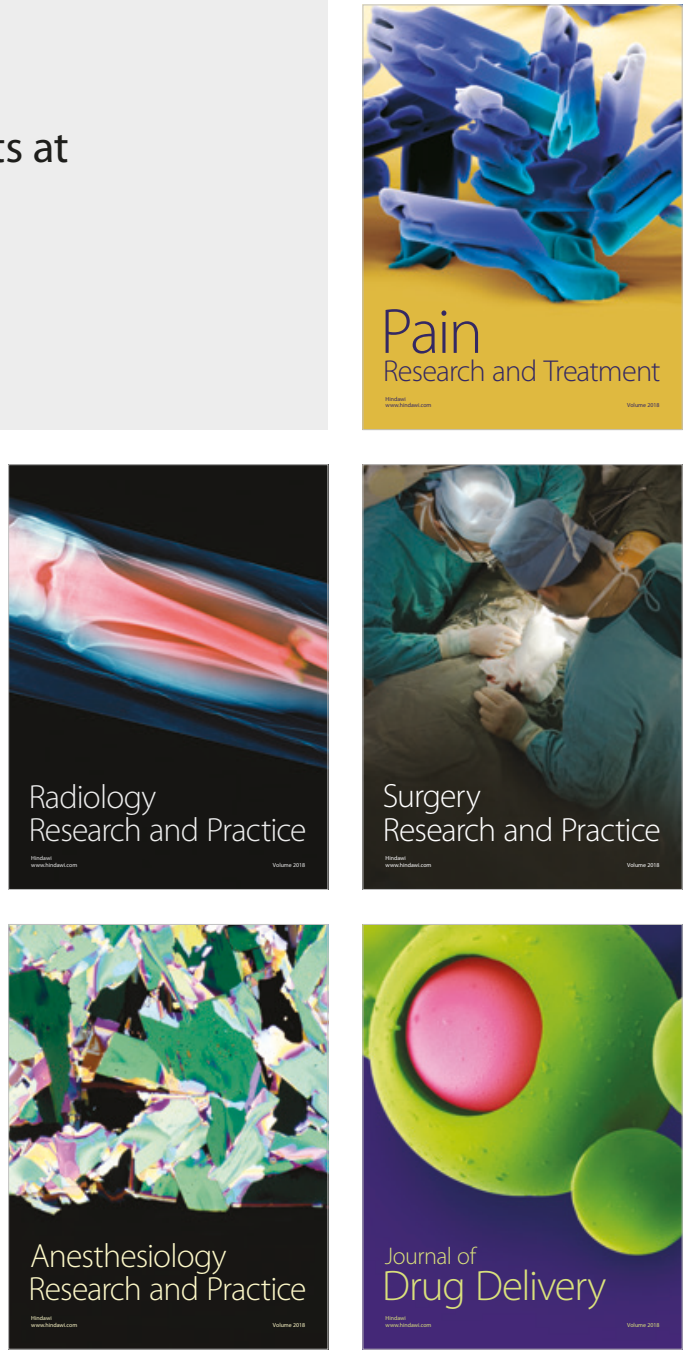